\title{
Community psychiatry in Portugal
}

\author{
JOSĖ MIGUEL CALDAS DE ALMEIDA
}

In the last thirty years, the development of mental health services in the community has been one of the main objectives of the different reorganisations of psychiatric services in Portugal.

The evolution of community psychiatry in the country during this period has been a particularly complex process, marked by uncountable difficulties which arose in connection with the changes that had taken place during this time in the economic, social and political spheres, and affected by various ideological and scientific influences.

In this evolution three distinct phases can be considerated. In the first phase (1963-1980), psychiatric services were decentralised. In the second phase (1980-1990), mental health services were integrated into the general health care system and a mental health reform was started. In the third phase (from 1990 onward), after an interruption of the reform, caused by changes on the political level, a wide debate was initiated on the objectives and foundations of a national mental health policy which allowed us to reach a consensus in this area.

\section{FIRST PHASE (1963-1980)}

In the early 60's, psychiatric care in the public service was provided almost exclusively by 5 psychiatric hospitals, with 3.700 beds, located in the three largest cities in the country. It was predominantly institutional and characterised by a lack of accessibility and a narrow range of available treatments. In the private sector, there were also 6 psychiatric institutions, owned by religious orders, with 3.100 beds, used mainly by chronic patients.

Indirizzo per la corrispondenza: Professor J.M. Caldas de Almeida, Clínica Universitária de Psiquiatria e Saúde Mental, Calçada da Tapada 155, 1300 Lisboa (Portugal).

Fax + $351-1-363.1264$.
The ratification in 1963 of the Law 2.118 (Presidência da República, 1963) based on principles which were very close to a community care approach, has changed this situation. Its main objective was the creation of an organisational structure - at the national, regional and local levels - capable of implementing, co-ordinating and providing comprehensive services aimed at promoting mental health, to prevent mental disorders and to treat and rehabilitate the mentally ill. The law, which was indisputably advanced for its time and for the political regime that existed then, also defined the rights of the individuals submitted to psychiatric treatment, giving the courts a decisive role regarding decisions on compulsory treatment.

According to Law 2.118, Mental Health Centres (MHC) became the basic structure of the mental health services. The Law envisaged the establishment of a MHC in each district and gave these centres the responsibility for all mental health care required by a defined population.

The MHC, according to this perspective, was, in fact, a service network capable of meeting different care needs of the population (including therefore in-patient facilities).

This model implied a restructuring of mental hospitals, but the law was not very clear regarding the way in which this should be accomplished. This ambiguity would have important consequences in the future. In effect, during the 60's and the 70's the implementation of the law led to the creation of MHC in all of the country's districts, with the exception of those in which mental hospitals were located.

In the beginning of the 80 's, 18 MHC had been established all over the country, covering $60 \%$ of the population ( 6 million people). On the regional level, special services (3) had been created for child mental health. The development of the MHC met with significant difficulties: the available resources were limited in most cases; the hiring of professionals, especially in interior areas, proved to be difficult; the integration in some of the centres of local 
asylum-style institutions hindered the development of community care.

Nevertheless, they profoundly changed the whole mental health services in the country. The local implementation of the new services has not only widely improved the accessibility of care for a large proportion of the population, but also made easier the development of new forms of intervention, more community-based and with a better liaison with other health services and social services. However, in the major cities - Lisbon, Oporto and Coimbra - where mental health care still depended on mental hospitals, the development of community care was very slow and continued to face great resistance.

\section{SECOND PHASE (THE 80's)}

A first attempt to overcome this situation was made in 1983, with the development of reorganisation plans for the areas of Lisbon and Oporto, but due to the resistance exerted by more traditional sectors of psychiatry, these plans were not implemented at that time. A very important step in the development of community psychiatry was taken with the creation of a National Health Service in 1984. Primary health care (provided by about 8,000 family doctors, 400 public health doctors and other health professionals in 340 Health Centres) became the fundamental basis of the health system. The integration in 1984 of mental health services in the General Directorate of Primary Care has ended the traditional separation of these services from the general health system, and made the formulation of a national mental health policy easier.

Two national plans for mental health, approved in 1985 and 1988 (Sampaio Faria, 1987; Ministério da Saúde, 1989; Caldas de Almeida, 1991) have brought to life this policy, aimed at the implementation of a mental health services reform, based on the following basic principles: 1. the development, in each catchment area, of a comprehensive and community-based care system; 2 . continuity of care; 3 . the integration and common administration of the different facilities (including those located in health centres and in general hospitals).

The mental health catchment areas were defined in order to correspond to the areas of the health centres, so that it would be possible for mental health teams to work together with the family doctors. Spe- cific areas for mental health teams started to be included in new health centres. At the same time, the inclusion of a psychiatric unit in all new general hospitals became mandatory. The implementation of this reform led to other significant advances: the development of a national information system on mental health services; the creation of structures for planning, monitoring and evaluating mental health services; the creation of the first MHC in Lisbon and Oporto as well as of several psychiatric units in general hospitals; the development of a wide training program for professionals in community psychiatry; the establishment of an inter-ministry (Health and Social Affairs) commission for the deinstitutionalisation and the rehabilitation of psychiatric patients that defined the basis for a program that allowed for the creation of rehabilitation facilities in several services. On the other hand, a mental health training program for family doctors was started on a national scale. Finally, due to the availability of financial resources specifically allocated for the development of community-based intervention projects, it has been possible to support a few innovative projects in the different regions of the country (day centres, prevention and rehabilitation programmes, epidemiological research projects).

\section{THIRD PHASE (FROM 1990 ON)}

In 1990, the whole restructuring process was interrupted. A change in government led to the adoption of a new orientation in mental health policy; an orientation based on a strict biomedical and hospital-centred model, and clearly opposed to the development of community services. Under the pretext of the importance of the general hospital for mental health care, MHC were abolished and administratively integrated into the hospitals of their respective areas. The bureaucratic constraints resulting from these measures and the lack of concern for community intervention programs shown by hospital administrations led to extremely negative results: most programs were stopped, mental health resources were drastically cut (Caldas de Almeida, 1993). Paradoxically, no new psychiatric units were created in general hospitals; on the contrary, some of the units that had been created were diverted to other medical specialities.

The development of a strong movement criticising 
this policy, with the participation of the National Association for Mental Health, of scientific associations and of professional associations has forced the government to recognise in 1994 the need for a change in policy in mental health.

A national debate, organised by the Ministry of Health, was held for almost a year, with wide participation by professionals, users and family representatives, and supported by international organisations (WHO, ERC-WFMN, WAPR). In May 1995, the final conference for this debate took place, where the consensual bases for the new mental health policy was formulated, a policy clearly influenced by the principles of community-based psychiatry, and having as main goal the development of comprehensive, community-centred and need-led mental health services (Ministério da Saúde, 1995).

\section{CONCLUSIONS}

The global evaluation of the evolution of mental health services in Portugal in the last 30 years shows that many of the objectives defined by the reform plans in the 60's and in the 80's have not been reached. Mental hospitals still are the only specialised services available to a significant part of the population, and they still consume most financial $(75 \%)$ and human resources. The development of new facilities in the community (day-centres, sheltered residences, etc.) is still very limited, and in some parts of the country totally non-existent. A large part of the population does not yet have access to services capable of meeting adequately their basic needs for mental health care.

In spite of this negative picture, we must recognise that there were some important advancements in this period. The number of beds in psychiatric hospitals has significantly decreased - in public hospitals it has been reduced from 3.984 in 1970 to 2.449 in 1993. Between 1982 and 1995, the number of beds per 1.000 population has gone from 1.02 to 0.66 in public and private services taken together. 450 psychiatric beds were created in general hospitals, although almost half of these are still not being used, due to the obstacles created by the policy that was followed after 1990 .

Thanks to the strategy of creating MHC, we have seen a progressive shift from care provided by mental hospitals to care provided by these centres, with all that this implies in terms of accessibility and implementation of community care.

In 1985, MHC were already responsible for more outpatient consultations (73.659) than psychiatric hospitals (68.047). In 1993, the difference was slightly higher - 129.169 in MHC (a 75\% increase) and 118.437 in psychiatric hospitals (a 72\% increase). This increase is particularly significant if we recall that one of the greatest difficulties facing MHC, after their administrative integration into general hospitals in 1990, was the development of outpatient consultation in health centres.

Regarding the number of admissions of in-patients in 1985, in the MHC there were 3.411 admissions per year (that is, about half that of psychiatric hospitals - 7.656).

However, if we look at the evolution that took place between 1985 and 1993, we will see a marked decrease in the number of admissions per year and in the number of inpatient days per year in psychiatric hospitals (from 7.656 to 7.237 , and from 930.383 to 709.197 , respectively); while in the MHC we will see an increase in the number of admissions per year (from 3.411 to 5.741), which is however accompanied by a decrease in de number of inpatient days per year (from 363.130 to 335.971 ).

Thus we can see that there has been a progressive decline in the role played by psychiatric hospitals, and a growing intervention by the MHC, not only at the level of ambulatory care, but also at the level of hospitalization.

Regarding the number of professionals, in 1990 the public services employed 616 psychiatrists (of which 217 were undergoing training), 1,288 nurses, 121 social workers, 67 psychologists and 52 occupational therapists. If we take into account the population of Portugal (10 million), we may conclude that the number of psychiatrists is already very large, but that other professionals still exist in very small numbers.

The evolution of the budget allocated for mental health services clearly shows the reduced importance that has been attributed to these services by successive governments (it has never gone much over $3 \%$ of the global budget for health services) and has followed the fluctuations of mental health policy. In effect, only between 1988 and 1989 was the percent increase of the mental health budget higher than that of the national health service, and after 1991 it reached the lowest level of the whole period under consideration.

A particularly positive aspect of the evolution in 
the last few years (specially in the last ten years) was the development of mental health care in the primary health care setting. Many mental health teams have developed liaison work schemes with the family doctors and have started to perform a significant part of their work in health centres. We have also registered important advances in the field of psychiatric rehabilitation. In this field, the European Community Horizon program has played a decisive role. It was mainly due to this program that vocational training programs could be developed and that the first cooperatives that appeared in the country could be created.

The growing participation of users and family representatives in the struggle for better mental health care and the ever increasing interest of professionals for psychiatric epidemiology and for mental care health care evaluation are recent trends which deserve special reference (Caldas de Almeida \& Xavier, 1995). We believe that they will be the most valuable supports for the future development of community psychiatry in Portugal.

In spite of all the difficulties and constraints actually in existence, we also believe that the more open attitude of the new government towards mental health problems will allow further developments in the mental health services reform in Portugal.

\section{REFERENCES}

Caldas de Almeida J. M. (1991). National reports - Portugal. In Evaluation of Comprehensive Care of the Mentally Ill (ed. $\mathrm{H}$ Freeman and J. Henderson), pp. 199-200. The Royal College of Psychiatrists: London.

Caldas de Almeida J.M. (1993). Développment des Services de Santé Mentale et Continuité des Soins. In Santé Mentale: Réalités Européennes (ed. C. Louzoun), pp. 39-42. Érès: Toulouse.

Caldas de Almeida J.M. \& Xavier M. (1995). Avaliação e garantia de qualidade dos serviços de saúde mental. Acta Médica Portuguesa $8,119-131$.

Ministério da Saúde (1989). Reorganização dos Serviços de Saúde Mental. Lisboa.

Ministério da Saúde (1995). Saúde Mental-Proposta para a Mudanca. Lisboa.

Presidência da República (1963). Lei $n^{\circledR} 2118$. Diário do Governo, $1^{a}$ Série, № 79. Lisboa.

Sampaio Faria J. G. (1987). Trends in organization of mental health care in Portugal. International Journal of Mental Health 16, 170-181. 